\title{
Educational Intervention on Breast Cancer Early Detection: Effectiveness among Target Group Women in the District of Gampaha, Sri Lanka
}

\author{
PVS Chiranthika Vithana $^{1 *}$, MAY Ariyaratne ${ }^{2}$, PL Jayawardana ${ }^{3}$
}

\begin{abstract}
Purpose: The present study concerns the effectiveness of an educational intervention for improving knowledge, attitudes and practices (KAP) of breast cancer early detection among target group women (TGW) in the district of Gampaha, Sri Lanka. Materials and Methods: The study was a community-based intervention. Two medical officer of health areas in Gampaha district were selected using random sampling as intervention (IA) and control (CA). Public health midwives (PHMs) in the IA were exposed to the educational intervention first, conducted the same among the TGW through PHMs. KAP was assessed using an interviewer- administrated questionnaire among 260 TGW from each area selected using cluster sampling before and six months after the intervention. Results: The overall median scores for KAP among TGW in IG increased significantly from pre intervention level of 54\% (IQR: 46-59\%), 50\% (IQR: 41-59\%), and 0\% (IQR: 0-20\%) to post intervention level of 77\% (IQR: 72-82\%), 68\% (IQR: 59- 76 \%) and 40\% (IQR: 20-60\%) respectively. In CG, overall median scores for KAP remained almost the same at pre intervention 54\% (IQR:44-59\%), 50\% (IQR:36-59\%) and 0\% (IQR: 0-20\%) and post intervention 54\% (IQR:46-59\%), 50\% (IQR:36-64\%) and 0\% (IQR: 0-20\%) respectively. Conclusions: The educational intervention was found to be effective.
\end{abstract}

Keywords: Breast cancer - well woman clinics - early detection - clinical breast examination - Sri Lanka

Asian Pac J Cancer Prev, 16 (6), 2547-2553

\section{Introduction}

According to the GLOBOCAN estimates, breast cancer is the most common cancer diagnosed among women and is the leading cause of female cancer deaths(Parkin et al., 2005; Benson and Jatoi, 2012; Bray et al., 2013; Ferlay et al., 2014). In Sri Lankan context, neoplasms are the third leading cause of hospital deaths(Ministry of Health, 2013). Breast cancer is the commonest cancer with an age standardized incidence rate of 18.8 per 100000 females in 2007 and accounted for $26 \%$ of newly diagnosed female cancers in 2007 (National Cancer Control Programme, 2013). It has the highest age-standardized mortality rate of 4.7 per 100,000 females in 2006 among female cancer patients (National Cancer Control Programme, 2013). Detection and intervention at early stage is the most effective way to increase the cure rate, prolong survival and reduce mortality due to breast cancer (Fung, 1998). Self-breast examination (SBE), clinical breast examination (CBE) and mammography are the three main strategies for early detection.

The opportunistic early detection of breast cancer was introduced to Sri Lanka in an organized manner with the concept of well woman clinics (WWCs) in 1996 (Family
Health Bureau, 2009). Breast cancer early detection is conducted using $\mathrm{CBE}$ and increasing awareness on SBE as mammographic facilities are costly and available only limited health facilities. WWCs are conducted by medical Officer of health $(\mathrm{MOH})$ with the assistance of Public Health Nursing Sister (PHNS) and Public Health Midwives (PHMs). PHM motivates women to attend WWC and performs CBE and educates community on SBE in WWC under the supervision of PHNS and $\mathrm{MOH}$. Women with breast abnormalities are referred to $\mathrm{MOH}$. Clients detected to have abnormalities are referred to specialist clinics. Area PHM will, thereafter, follow up the women in the field and ensure that the necessary instructions are followed by them.

Despite having 54 functioning WWCs in the Gampaha district in 2008, only 2.2\% of women aged 35-59 years had undergone screening in 2007 (Vithana et al., 2013a). Entire district was found be substandard in relation to CBE and SBE in a quality assessment component on breast cancer early detection services, conducted in $20 \mathrm{WWCs}$ in the Gampaha District using lot quality assurance sampling in the first phase this study (Vithana et al., 2013a).

A cross-sectional survey conducted among 219 female health care workers (with $68.9 \%$ of the sample consisting 
of PHMs) selected from six districts in Sri Lanka revealed that only $47.9 \%$ of them practiced SBE on a monthly basis, $19.2 \%$ had undergone a CBE within one year and $3.6 \%$ had ever undergone a mammography (Nilaweera et al., 2012).

Sensitivity and specificity of CBE and SBE depend on how accurately these procedures are performed (Wilke et al., 2009). Qualitative research using four focus group discussions among PHMs conducted in 2008 in the Gampaha district, identified inadequacy of training, lack of skills and material to provide health education, inability to provide privacy during $\mathrm{CBE}$, and lack of community awareness and motivation. Suggestions came-out were training of PHMs using evidence-based learning and teaching technics, provision of modern health education materials and strengthening of monitoring and supervision (Vithana et al., 2013b) of the services.

An educational intervention was conducted to overcome the above issues and was found to be effective in increasing the knowledge, attitudes and practices on breast cancer early detection among PHMs provided through WWCs in the Gampaha district (Vithana et al., 2015). The present paper describes the assessment of effectiveness of PHMs on improving knowledge, attitudes and practices on breast cancer early detection among target group women (TGW) aged 35-59 years in the community in the Gampaha district.

\section{Materials and Methods}

This is the second component of a community based interventional study conducted in 2009 in the Gampaha district. First component of it consisted of designing and implementation of the intervention and the assessment of the effectiveness of the intervention on improving knowledge, attitudes and practices on early detection of breast cancer among PHMs (Vithana et al., 2015) as mentioned above. Present component is on assessing the effectiveness of the trained PHMs on improving early detection of breast cancer among target group women aged $35-59$ years in the community.

The description of the study setting has been given in a previous article (Vithana et al., 2015) The $14 \mathrm{MOH}$ areas of the district was stratified according to urban, rural and estate sectors (this was done to ensure that the pair of $\mathrm{MOH}$ areas selected for the final sample was comparable in relation to the sector). Then the non bordering $\mathrm{MOH}$ areas of each stratum were paired (as the number of $\mathrm{MOH}$ areas in each stratum consisted of even numbers, pairing was made easy). Applying simple random sampling to all the pairs (irrespective of the sector), the pair selected finally was Divulapitiya and Attanagalla which belonged to the rural sector. The intervention (Divulapitiya MOHIG) and control (Attanagalle MOH-CG) areas within the selected pair, was also chosen randomly.

Study participants consisted of 260 target group women aged 35-59 years who were selected using cluster sampling from each study area. The primary sampling unit was the PHM areas from the intervention and control areas. Cluster size was considered as 10 which was the number possible to be interviewed on a single day. The 26 clusters from the two selected areas were selected based on probability proportion to size applying systematic sampling technique.

Relevant data were collected using a pre-tested interviewer administrated questionnaire (IAQ) which consisted of socio demographic data and knowledge, attitudes and practices related to breast cancer early detection. The educational intervention was conducted through the PHMs of the intervention area who underwent similar training (details are available in the same article authored by Vithana et al. [2015]) mentioned above. The Training package including "Trainers' Guide" for conducting training for PHMs and a handbook for the PHMs to conduct educational intervention were developed. They were trained using evidence-based teaching and learning technics. A "checklist on breast cancer screening" with a colour code of four colours to assess breast cancer screening status of individual clients was also developed.

PHMs implemented the intervention in the community six months following their training. This component of the intervention was meant for all the target group population in the intervention area and was conducted for the target group women in all the WWC clinics, during home visits and at every point of contact during the period between 01.01.2009 to 01.07.2009.

The main tool for the intervention was the "checklist on breast cancer screening". It was to promote breast cancer screening practices among women in the community. This has to be filled in by the PHM and the client. The information that had to be recorded by the PHM were 1) a preliminary assessment of risk status based on the history of presence of 11 risk factors and assessment of screening status based on 2) being subjected to CBE (once with in the past year) and 3) practicing SBE monthly 4) undergone any other breast cancer early detection test 5) recording of any referrals made by PHM as per relevance. The client was expected to chart each SBE conducted in the space provided.

The colour codes used were as follows: red (not performed SBE monthly, not undergone CBE within one year and never undergone mammography), orange (practicing SBE monthly but not undergone CBE within one year or never undergone mammography), yellow (had CBE within one year or undergone mammography at least once but not practicing SBE monthly) and green (had CBE within one year or undergone mammography at least once and practicing SBE monthly). Assistance of the supervisory staff was sought to monitor the intervention during their routine supervision.

Same IAQ used for pre intervention was used for post intervention assessment of both IG and CG six months after implementation of the intervention in the intervention area. Data collection was conducted by six retired PHMs (who were expected to have no conflict of interest as they were no longer in active service).

Checking for inconsistencies and incompleteness was conducted immediately after IAQ was filled. Data entry and entire data processing was done using Epi Data V 2.2 and SPSS Version 15 statistical software. Validity checks were included at every possible site during the data entry to avoid errors. Scoring system was developed 
Educational Intervention for Breast Cancer Early Detection: Effectiveness in the District of Gampaha, Sri Lanka

to assess knowledge, attitudes and practices with expert participation. Attitude was marked using a 4 point Likert scale: very favorable $(+2)$, favourable $(+1)$, un- favourable $(-1)$ and very unfavourable $(-2)$. Percentage scores of overall scores for individual components of knowledge, attitudes and practices were calculated by adding up the individual item scores of the relevant components and expressing it as a percentage of the total score possible. .

As overall scores on assessment of knowledge, attitudes and practices were not distributed normally, the results are presented as median values with respective inter quartile ranges (IQR). Comparison of the scores between two groups was carried-out using Mann Whitney U test. Wilcoxon Signed Rank test was used for pre and post comparisons of IG and CG separately. Comparisons between groups for categorical variables were conducted using Chi-Square test and Fisher's exact test.

Informed written consent was obtained from all participants before conducting the intervention. All the information obtained in the study was treated as confidential and used only for the research purpose. Results of the study were made available to National Cancer Control Programme and Family Health Bureau to facilitate improving breast cancer early detection services of the WWCs. Ethical clearance was obtained from the Ethics Review Committee of the Faculty of Medicine, University of Kelaniya.

\section{Results}

Participants for pre intervention survey consisted of $260 \mathrm{TGW}$ from each arm. For post-intervention survey $258(99.2 \%)$ women were available from the IG and 259 (99.6\%) from the CG.

Selected characteristics of target group women of $I G$ and $C G$

Median age of the women in IG was 43 (IQR $=38$ 50) years and in CG 43 ( $\mathrm{SD}=39-50)$ years. In IG $99.6 \%$ $(\mathrm{n}=259)$ and in CG $99.2 \%(\mathrm{n}=258)$ were Sinhalese. In IG $82.3 \%(n=214)$ and in CG $87.3 \%(n=227)$ Buddhists. The highest proportion in both IG $(41.5 \% ; n=108)$ and in CG (40.8\%; $n=106)$ had educational level between Grades 10 -11. In IG, $91.5 \%(\mathrm{n}=238)$ and in $\mathrm{CG}, 87.5 \%(\mathrm{n}=227)$ were currently married. In IG, $15.4 \%(\mathrm{n}=40)$ and in $\mathrm{CG}, 12.3 \%$ $(n=32)$ were employed. None of the above differences in

Table 1. Pre and Post-intervention Comparison of Knowledge on Risk Factors for Breast Cancer among Target Group in the Intervention (IG) and Control (CG) Groups

\begin{tabular}{|c|c|c|c|c|c|c|}
\hline \multirow[t]{2}{*}{ Risk factors } & \multicolumn{3}{|c|}{ Pre-intervention } & \multicolumn{3}{|c|}{ Post-intervention } \\
\hline & $\begin{array}{c}\mathrm{IG} \\
(\mathrm{N}=260)\end{array}$ & $\begin{array}{c}\mathrm{CG} \\
(\mathrm{N}=260)\end{array}$ & Significance & $\begin{array}{c}\text { IG } \\
(\mathrm{N}=258)\end{array}$ & $\begin{array}{c}\mathrm{CG} \\
(\mathrm{N}=259)\end{array}$ & Significance \\
\hline \multicolumn{7}{|l|}{ 1. Obesity } \\
\hline Correct & $43(16.5 \%)$ & $35(13.5 \%)$ & $\chi^{2}=0.965$ & $169(65.5 \%)$ & $44(17 \%)$ & \multirow{2}{*}{$\begin{aligned} \chi^{2}=125.58 \\
p<0.001\end{aligned}$} \\
\hline Incorrect/Do not know & $217(83.5 \%)$ & $225(86.5 \%)$ & $\mathrm{p}=0.326$ & $89(34.5 \%)$ & $215(83 \%)$ & \\
\hline \multicolumn{7}{|c|}{ 2. Prolonged use of Oral Contraceptive Pills/ Hormone Replacement Therapy } \\
\hline Correct & $88(33.8 \%)$ & $100(38.5 \%)$ & $\chi^{2}=1.2$ & $207(80.2 \%)$ & $107(41.3 \%)$ & \multirow{2}{*}{$\begin{aligned} \chi^{2} & =82.1 \\
p & <0.001\end{aligned}$} \\
\hline $\begin{array}{l}\text { Incorrect/Do not know } \\
\text { 3. Early menarche }\end{array}$ & $172(66.2 \%)$ & $160(61.5 \%)$ & $\mathrm{p}=0.273$ & $51(19.8 \%)$ & $152(58.7 \%)$ & \\
\hline Correct & $25(9.6 \%)$ & $20(7.7 \%)$ & $\chi^{2}=0.608$ & $170(65.9 \%)$ & $22(8.5 \%)$ & \multirow{2}{*}{$\begin{array}{r}\chi^{2}=182.39 \\
p<0.001\end{array}$} \\
\hline \multicolumn{6}{|l|}{ 4. Late menopause } & \\
\hline Correct & $64(24.6 \%)$ & $60(23.1 \%)$ & $\chi^{2}=0.169$ & $174(67.4 \%)$ & $59(22.8 \%)$ & \multirow{2}{*}{$\begin{array}{r}\chi^{2}=104.14 \\
p<0.001\end{array}$} \\
\hline \multicolumn{6}{|l|}{ 5. Not given births } & \\
\hline Correct & $135(51.9 \%)$ & $145(55.8 \%)$ & $\chi^{2}=0.774$ & $212(82.2 \%)$ & $143(55.2 \%)$ & \multirow{2}{*}{$\begin{aligned} \chi^{2} & =43.66 \\
p & <0.001\end{aligned}$} \\
\hline $\begin{array}{l}\text { Incorrect/Do not know } \\
6 . \text { Hereditary }\end{array}$ & $125(48.1 \%)$ & $115(44.2 \%)$ & $\mathrm{p}=0.379$ & $46(17.8 \%)$ & $116(44.8 \%)$ & \\
\hline Correct & $148(56.9 \%)$ & $134(51.5 \%)$ & $\chi^{2}=1.519$ & $229(88.8 \%)$ & $136(52.5 \%)$ & \multirow{2}{*}{$\begin{aligned} \chi^{2} & =81.83 \\
p & <0.001\end{aligned}$} \\
\hline Incorrect/Do not know & $112(43.1 \%)$ & $126(48.5 \%)$ & $\mathrm{p}=0.218$ & $29(11.2 \%)$ & $123(47.5 \%)$ & \\
\hline \multicolumn{7}{|c|}{ 7. First pregnancy after 30 years } \\
\hline Correct & $30(11.5 \%)$ & $50(19.2 \%)$ & $\chi^{2}=5.909$ & $154(59.7 \%)$ & $53(20.5 \%)$ & \multirow{2}{*}{$\begin{aligned} \chi^{2} & =82.84 \\
p & <0.001\end{aligned}$} \\
\hline Incorrect/Do not know & $230(88.5 \%)$ & $210(80.8 \%)$ & $\mathrm{p}=0.015$ & $104(40.3 \%)$ & $206(79.5 \%)$ & \\
\hline \multicolumn{7}{|c|}{ 8. Family history of ovarian cancer } \\
\hline Correct & $8(3.1 \%)$ & $5(1.9 \%)$ & $\chi^{2}=0.71$ & $92(35.7 \%)$ & $7(2.7 \%)$ & \multirow{2}{*}{$\begin{aligned} \chi^{2} & =90.67 \\
p & <0.001\end{aligned}$} \\
\hline Incorrect/Do not know & $252(96.9 \%)$ & $255(98.1 \%)$ & $\mathrm{p}=0.399$ & $166(64.3 \%)$ & $252(97.3 \%)$ & \\
\hline \multicolumn{7}{|c|}{ 9. Past history of breast cancer } \\
\hline Correct & $147(56.5 \%)$ & $134(51.5 \%)$ & $\chi^{2}=1.309$ & $229(88.8 \%)$ & $136(52.5 \%)$ & \multirow{2}{*}{$\begin{aligned} \chi^{2} & =81.83 \\
p & <0.001\end{aligned}$} \\
\hline Incorrect/Do not know & $113(43.5 \%)$ & $126(48.5 \%)$ & $\mathrm{p}=0.253$ & $29(11.2 \%)$ & $123(47.5 \%)$ & \\
\hline \multicolumn{7}{|c|}{ 10. Prolonged breast feeding } \\
\hline Correct & $186(71.5 \%)$ & $165(63.5 \%)$ & $\chi^{2}=3.866$ & $193(74.8 \%)$ & $141(54.4 \%)$ & \multirow{2}{*}{$\begin{array}{r}\chi^{2}=23.444 \\
p<0.001\end{array}$} \\
\hline $\begin{array}{l}\text { Incorrect/Do not know } \\
\text { 11. Having more childre }\end{array}$ & $74(28.5 \%)$ & $95(36.5 \%)$ & $\mathrm{p}=0.049$ & $65(25.2 \%)$ & $118(45.6 \%)$ & \\
\hline Correct & $148(56.9 \%)$ & $143(55 \%)$ & $\chi^{2}=0.195$ & $216(83.7 \%)$ & $152(58.7 \%)$ & \multirow{2}{*}{$\begin{array}{r}\chi^{2}=39.484 \\
p<0.001\end{array}$} \\
\hline Incorrect/Do not know & $112(43.1 \%)$ & $117(45 \%)$ & $\mathrm{p}=0.659$ & $42(16.3 \%)$ & $107(41.3 \%)$ & \\
\hline
\end{tabular}


the two groups were statistically significant.

Knowledge on risk factors for breast cancer (Table 1)

The proportion of correct responses for the all items were similar in the two groups at pre-intervention stage except for the questions on "first pregnancy after 30 years" which had a significantly higher proportion of correct responses among the $\mathrm{CG}$ and for correct knowledge that "prolonged breast feeding is not a risk factor for breast cancer" was significantly higher in IG. At the post intervention stage a significantly higher proportion of correct responses were observed in IG than CG for all the items $(\mathrm{p}<0.001)$. In the $\mathrm{CG}$, the correct response rate remained almost similar to that of the pre intervention rate.

Overall scores on knowledge on breast cancer and early detection (Table 2 and Table 3)

The median value of percentage scores on knowledge on symptoms was significantly higher among the CG (median score=57.1\%; IQR: $42.9-71.4 \%$ ) than IG (median score=42.9\%; IQR: 42.9-57.1\%) in pre intervention assessment $(\mathrm{p}<0.05)$. None of the scores of other components (knowledge on breast cancer, its risk factors, early detection measures and consequences of late

Table 2. Comparison of Knowledge, Attitude and Practices Scores on Breast Cancer Early Detection among women in the Target Community in the Intervention (IG) and Control (CG) Groups

\begin{tabular}{|c|c|c|c|c|c|c|}
\hline \multirow[t]{2}{*}{$\begin{array}{l}\text { Knowledge } \\
\text { Components }\end{array}$} & \multirow{2}{*}{$\begin{array}{c}\text { Percentage Score } \\
\text { Pre intervention } \\
\text { IG } \\
\text { Median } \\
\text { IQR }\end{array}$} & \multicolumn{5}{|c|}{ Post intervention } \\
\hline & & $\begin{array}{c}\text { CG } \\
\text { Median } \\
\text { IQR }\end{array}$ & Significance & $\begin{array}{c}\text { IG } \\
\text { Median } \\
\text { IQR }\end{array}$ & $\begin{array}{c}\text { CG } \\
\text { Median } \\
\text { IQR }\end{array}$ & Significance \\
\hline Overall knowledge & $\begin{array}{c}53.8 \\
46.2-59.0\end{array}$ & $\begin{array}{c}53.8 \\
43.6-59.0\end{array}$ & $\mathrm{p}=0.94$ & $\begin{array}{c}76.9 \\
71.8-82.1\end{array}$ & $\begin{array}{c}53.9 \\
46.2-59.0\end{array}$ & $\mathrm{p}<0.001$ \\
\hline $\begin{array}{l}\text { Overall } \\
\text { Attitude }\end{array}$ & $\begin{array}{c}50 \\
40.9-59.1\end{array}$ & $\begin{array}{c}50 \\
36.4-59.1\end{array}$ & $\mathrm{p}=0.947$ & $\begin{array}{c}68.2 \\
59.1-76.1\end{array}$ & $\begin{array}{c}50 \\
36.4-63.6\end{array}$ & $\mathrm{p}<0.001$ \\
\hline $\begin{array}{l}\text { Practicing Breast Cancer } \\
\text { Screening }\end{array}$ & $\begin{array}{c}0 \\
0.0-20.0\end{array}$ & $\begin{array}{c}0 \\
0.0-20.0\end{array}$ & $\mathrm{p}=0.217$ & $\begin{array}{c}40 \\
20.0-60.0\end{array}$ & $\begin{array}{c}0 \\
0.0-20.0\end{array}$ & $\mathrm{p}<0.001$ \\
\hline
\end{tabular}

*Statistical test: Mann Whitney U Test (between IG and CA at pre intervention and post intervention six months seperatly)

Table 3. Within Group Comparison of Knowledge, Attitude and Practices Scores on Breast Cancer Early Detection among Women in the Target Community in the Intervention (IG) and Control (CG) Separately

\begin{tabular}{|c|c|c|c|c|}
\hline \multirow[t]{2}{*}{ Knowledge Components } & \multirow[b]{2}{*}{ Area } & \multicolumn{3}{|c|}{ Percentage Scores } \\
\hline & & $\begin{array}{c}\text { Pre intervention } \\
\text { Median IQR }\end{array}$ & $\begin{array}{l}\text { Post intervention } \\
\text { Median IQR }\end{array}$ & Significance \\
\hline \multirow[t]{2}{*}{ Overall knowledge } & Intervention & $53.8(46.2-59.0)$ & $76.9(71.8-82.1)$ & $\mathrm{p}<0.001$ \\
\hline & Control & $53.9(43.6-59.0)$ & $53.9(46.2-59.0)$ & $\mathrm{p}=0.843$ \\
\hline \multirow[t]{2}{*}{ Overall Attitude } & Intervention & $50(40.91-59.09)$ & $68.2(59.1-76.1)$ & $\mathrm{p}<0.001$ \\
\hline & Control & $50(36.4-59.1)$ & $50(36.4-63.6)$ & $\mathrm{p}=0.492$ \\
\hline \multirow[t]{2}{*}{ Practicing breast cancer Screening } & Intervention & $0(0.0-20,0)$ & $40(20.0-60.0)$ & $\mathrm{p}<0.001$ \\
\hline & Control & $0(0.0-20.0)$ & $0(0.0-20.0)$ & $\mathrm{p}=0.071$ \\
\hline
\end{tabular}

*Statistical test: Wilcoxon signed rank test (within IG and CG separately: pre intervention with post intervention six months)

Table 4. Practices of Early Detection Measures of Breast Cancer among Women in the Target Community in Intervention (IG) and Control (CG) Groups

\begin{tabular}{|c|c|c|c|c|c|c|}
\hline \multirow[t]{2}{*}{ Practices Items } & \multicolumn{3}{|c|}{ Pre intervention } & \multicolumn{3}{|c|}{ Post intervention } \\
\hline & $\begin{array}{c}\mathrm{IG} \\
(\mathrm{N}=260)\end{array}$ & $\begin{array}{c}\mathrm{CG} \\
(\mathrm{N}=260)\end{array}$ & $P$ value & $\begin{array}{c}\mathrm{IG} \\
(\mathrm{N}=258)\end{array}$ & $\begin{array}{c}\mathrm{CG} \\
(\mathrm{N}=259)\end{array}$ & $\mathrm{P}$ value \\
\hline \multicolumn{7}{|c|}{ Ever undergone CBE } \\
\hline Yes & $53(20.4 \%)$ & $40(15.4 \%)$ & $*$ & $143(55.4 \%)$ & $43(16.6 \%)$ & $*$ \\
\hline No & $207(79.6 \%)$ & $220(84.6 \%)$ & $\mathrm{p}=0.137$ & $115(44.6 \%)$ & $216(83.4 \%)$ & $\mathrm{p}<0.001$ \\
\hline \multicolumn{7}{|c|}{ Undergone CBE within previous one year } \\
\hline Yes & $7(2.7 \%)$ & $6(2.3 \%)$ & $*$ & $98(38.0 \%)$ & $9(3.5 \%)$ & $*$ \\
\hline No & $253(97.3 \%)$ & $254(97.7 \%)$ & $\mathrm{p}=0.779$ & $160(62.0 \%)$ & $250(96.5 \%)$ & $\mathrm{p}<0.001$ \\
\hline \multicolumn{7}{|l|}{ Practicing SBE } \\
\hline Yes & $95(36.5 \%)$ & $92(35.4 \%)$ & $*$ & $219(84.9 \%)$ & $93(35.9 \%)$ & $*$ \\
\hline No & $165(63.5 \%)$ & $168(64.5 \%)$ & $\mathrm{p}=0.784$ & $39(15.1 \%)$ & $166(64.1 \%)$ & $\mathrm{p}<0.001$ \\
\hline \multicolumn{7}{|c|}{ Practicing SBE monthly } \\
\hline Yes & $18(6.9 \%)$ & $21(8.1 \%)$ & $*$ & $117(45.3 \%)$ & $27(10.4 \%)$ & $*$ \\
\hline No & $242(93.1 \%)$ & $239(91.9 \%)$ & $\mathrm{p}=0.617$ & $141(54.7 \%)$ & $232(89.6 \%)$ & $\mathrm{p}<0.001$ \\
\hline \multicolumn{7}{|c|}{ Undergone Mammography } \\
\hline Yes & $2(0.8 \%)$ & $3(1.2 \%)$ & $* *$ & $2(0.8 \%)$ & $3(1.2 \%)$ & $* *$ \\
\hline No & $258(99.2 \%)$ & $257(98.8 \%)$ & $\mathrm{p}=1.000$ & $256(99.2 \%)$ & $256(98.8 \%)$ & $\mathrm{p}=1.000$ \\
\hline
\end{tabular}

Statistical test: *Chi square test; ** Fisher exact test CBE - Clinical Breast Examination; SBE - Self Breast Examination 
detection) and overall score differed significantly.

At post intervention, the scores of the entire component, as well as the overall score were significantly higher among the IG in comparison to $\mathrm{CG}(\mathrm{p}<0.001)$. The median value of percentage scores of the $\mathrm{CG}$ remained same as at pre intervention stage. Median scores of all components as well as the overall score in IG had increased significantly $(\mathrm{p}<0.001)$ at post intervention.

Attitude among TGW on breast cancer early detection in IA and CA (Table 2 and 3)

At pre intervention, all the median value of percentage scores (for attitudes on benefits of screening, barriers for screening, perception on services provided by WWC and overall attitude) were the same in both IG and CG except for the component on "their susceptibility for breast cancer and severity of the breast cancer" where the CG had significantly $(\mathrm{p}=0.006)$ higher scores than in IG. At post intervention, all the scores were significantly higher in IG than $\mathrm{CG}(\mathrm{p}<0.001)$

Within IG, median scores of all components (for attitudes on their susceptibility for breast cancer and severity of breast cancer, benefits of screening, perception on services provided by WWC and overall attitudes) except for "barriers for screening", as well as the overall score had increased significantly with a $\mathrm{P}<0.001$. For "barriers for screening", median score remained same at pre and post intervention with a significant increase in IQR $(\mathrm{p}<0.001)$. In $\mathrm{CG}$, median scores of all components as well as the overall score had remained the same or decreased.

Practices of breast cancer early detection among TGW in IA and CA (Tables 2, 3 and 4)

There was no difference between the practices related to breast cancer early detection among IG and CG at pre intervention. At post intervention a significantly higher proportion $(\mathrm{p}<0.001)$ of those in the IG had undergone $\mathrm{CBE}$ and was practicing SBE. Yet, the proportion who underwent mammography remained the same at pre and post intervention in both IG and CG.

Comparison of scores for breast cancer early detection practices (Table 2 and 3 )

Median value of percentage scores on practicing breast cancer early detection was $0 \%$ with an $\mathrm{IQR}=0-20 \%$ in both areas at pre intervention stage. At post intervention median value of percentage scores in IG increased to 40\% (IQR: $20-40 \%$ ) and in CG it remained at 0 (IQR: $0-20 \%)$. The difference of the latter two was statistically significant $(\mathrm{p}<0.001)$. Within the IG, the median value of the percentage scores on practices showed a statistically significant increase from pre to post intervention stage. Within CG no change was observed between pre and post intervention stages.

\section{Discussion}

Educational intervention conducted through the PHMs was found to be effective in improving knowledge, attitudes and practices on early detection of breast cancer among the target group women.
The results of this study are considered internally valid as maximum effort was taken to minimize selection, information and confounding bias. Initial stratification according to sectors ensured the required comparability as the socio-demographic characteristics unique to urban, rural and estate settings were ensured by this process. The study pair was selected randomly and the intervention was assigned on a random basis within the chosen pair. Randomization contributes to control of confounding factors as well as mitigating selection bias between the two settings, in that purposive selection might have led to unconscious selection of the better setting to apply the intervention. Absence of selection bias is thus evident from the fact that the $\mathrm{CG}$ had better scores in relation to knowledge on first childbirth after 30 years being a risk factor and on symptoms of breast cancer. Five out of 47 PHMs in the control area has had some training on breast cancer early detection in the past before the intervention, which may account for this (Vithana et al., 2015).

Contamination which occurs due to communication about the intervention between the IG and CG was minimized by identifying and pairing the non-bordering $\mathrm{MOH}$ areas which belonged to the same strata. This was more applicable to the target group women rather than the PHMs because PHMs are likely to meet at various training programmes conducted for the district staff. Despite above, the results very clearly indicated, absence of contamination as the test scores of the $\mathrm{CG}$ remained almost the same at pre and post intervention for both the PHMs (Vithana et al., 2015) and target group women.

Repeated application of the same study instruments is likely to lead an improvement in responses to subsequent measurements. This was controlled for by having the CG as both groups were subjected same number of testing. History effect which results from the presence of external factors other than the intervention was also controlled for by having the CG.

Short follow up of six months was a limitation. A longer follow up period was not feasible due to logistical reasons. The sustainability of gain in knowledge, attitudes and practices can only be explored through an extended period of observation. However, having a study period limited to six months minimized the effect of maturation, a phenomenon that make people perform better or worse due to the natural growing process such as growing more wise or getting exhausted, which is likely to change the manner in which the respondents would react to the independent variable assessed. Having the CG helped to control for this maturation effect as well.

Monitoring of the intervention was conducted through existing system of area supervisory staff in both groups, which helped to reduce introducing a bias due to the Hawthorne effect. All measures were taken to meet with the increased demands for service provision in both IG and CG, which was essential to win the confidence of the clients, and thus sustained participation in the screening programme.

The loss to follow up rate was as low as less than $1 \%$ in the two groups $(0.8 \%$ in IG and $0.4 \%$ in $\mathrm{CG})$ and on comparison of basic socio demographic characteristics no significant differences were observed between those 
PVS Chiranthika Vithana et al

lost to follow up and those remaining in relation to within and between group comparisons..These comparisons and the high participant rates ensured both external (as IG and CG were selected using probability sampling) and internal validity of the study. External validity enables the results of this study to be generalized to the entire district of Gampaha.

Pre intervention knowledge on one risk factor and symptoms were significantly $(\mathrm{p}=.02)$ higher among the CG., Five out of 47 PHMs in the control area has had some training on breast cancer on early detection in the past, which may account for this (Vithana et al., 2015). Other components and the overall knowledge scores were almost the same in the two groups at pre intervention. Effectiveness of the intervention is evident from the post intervention results, where individual components as well as overall knowledge showed significant improvement ( $p<0.001$ for all variables) in IG when the scores in CG remained same as that of pre intervention

A similar picture was seen for attitudes too, where the CG had significantly better scores at pre intervention for the components on "susceptibility and severity", but at post intervention all the components of attitudes among IG, demonstrated a significant improvement, in comparison to $\mathrm{CG}$.

With regard to practices, however, the picture observed in relation to pre intervention was different where both IG and CG did not differ significantly. This means that even though the five PHMs who had undergone training previously in the CG could make a significant difference in relation to knowledge and attitudes, the impact on practices had been poor. When analysing the results at post intervention, similar to knowledge and attitudes, the intervention had made a significant improvement of on practices related to CBE and SBE as well. This clearly demonstrates the need of an impetus provided by the service providers in motivating target group women to make maximum use of the available services.

The intervention was targeted through the PHMs who were trained for the purpose. Their primary duty revolves around providing first contact care to pregnant mothers, infants and pre-school children in addition to family planning services delivered through domiciliary visits paid on a regular basis. They are also involved in health promotion activities and educating the community regarding health and health related activities. They provide a link to the main health care system through clinic services conducted in the respective $\mathrm{MOH}$ areas. One such service is rendered through the WWCs with the main objective of screening for four major non communicable diseases afflicting females; namely diabetes mellitus, hypertension and cancer of cervix and breasts.

All above activities conducted through domiciliary visits make the PHM very close to the community. Well acceptance of the PHM in the community and the rapport built, helps to enhance a two way communication, which is recognized to be more suitable for behavior changed communication (Redding et al., 2003).

The close monitoring of the target group women was achieved through the use of "checklist on breast cancer screening", which ensured regular contact with the study participants. The assessment of risk status certainly would have made a greater impetus on those who were identified as high risk clients to actively to seek services. The use of the colour codes which assessed screening practices and clinic visit status, would have motivated women further to be conscious of their health status. Thus close monitoring of the target group women obviously had demonstrated an impact on changing their health seeking behavior making them more keen to patronize the services, the value of which was not recognized earlier, even though provided totally free of charge.

The use of this type of colour code and its effectiveness had been described in the literature as well. In the USA, an intervention designed by Cancer Screening Office Systems (Cancer SOS), to increase cancer screening in primary care settings serving disadvantaged populations in Hills-borough County, Fla, Florida, had been reported to be effective (Roetzheim et al., 2004), which is consistent with the results of the present study.

As overall scores computed had a highly skewed distribution, median values and the respective IQRs were used as summary measures. Hence T Mann-Whiteny U and Wilcoxon signed-rank tests which are non parametric tests were used to compare unpaired and paired data respectively.

In conclusion, using trained PHMs through an educational intervention to improve knowledge, attitudes and practices related to breast cancer early detection among the target group women was proven to be effective. Recommends incorporation of the present educational intervention with a check list with colour codes into the existing system for betterment of breast cancer early detection services.

\section{References}

Benson JR, Jatoi I (2012). The global breast cancer burden. Future Oncol, 8, 697-702.

Bray F, Ren JS, Masuyer E, et al (2013). Global estimates of cancer prevalence for 27 sites in the adult population in 2008. Int J Cancer, 132, 1133-45.

Ferlay J, Soerjomataram I, Dikshit R, et al (2014). Cancer incidence and mortality worldwide: Sources, methods and major patterns in GLOBOCAN 2012. Int J Cancer, 136, 359-86

Fung SY (1998). Factors associated with breast self-examination behaviour among Chinese women in Hong Kong. Patient Education and Counselling, 33, 233-43.

Ministry of Health SL. 2013. Hospital mortality [Online]. Colombo, Sri Lanka: Ministry of Health, Sri Lanka. Available: http://www.health.gov.lk/en/index.php?option=com_content $\&$ view $=$ article $\& i d=372 \&$ Itemid $=141$ [Accessed 12,10 2013] National Cancer Control Programme Sri Lanka (2012). Cancer incidence data: Sri Lanka Year 2007. Available: http://www. health.gov.lk/en/index.php?option=com content $\&$ view $=$ art icle $\&$ id $=372 \&$ Itemid $=141$ [Accessed 12,10 2013].

Nilaweera RI, Perera S, Paranagama N, et al (2012). Knowledge and practices on breast and cervical cancer screening methods among female health care workers: a Sri Lankan experience. Asian Pac J Cancer Prev, 13, 1193-6.

Parkin DM, Bray F, Ferlay J, et al (2005). Global cancer statistics, 2002. CA Cancer J Clin, 55, 74-108. 
Redding CA, Rossi JS, Rossi SR, et al (2003). Health behavior models. Int Electronic J Health Education, 2000, 180-93.

Roetzheim RG, Christman LK, Jacobsen PB, et al (2004). A randomized controlled trial to increase cancer screening among attendees of community health centers. Ann Fam Med, 2, 294-300.

Vithana PV, Ariyaratne M, Jayawardana P (2013a). Quality of breast cancer early detection services conducted by well woman clinics in the district of Gampaha, Sri Lanka. Asian Pac J Cancer Prev, 14, 75-80.

Vithana PV, Hemachandra NN, Ariyaratne Y, et al (2013b). Qualitative assessment of breast cancer early detection services provided through well woman clinics in the district of Gampaha in Sri Lanka. Asian Pac J Cancer Prev, 14, 7639-44.

Vithana PC, Ariyaratne M, Jayawardana P (2015). Effectiveness of an educational intervention among public health midwives on breast cancer early detection in the district of gampaha, Sri Lanka. Asian Pac J Cancer Prev, 16, 227-32.

Wilke LG, Broadwater G, Rabiner S, et al (2009). Breast selfexamination: defining a cohort still in need. Am J Surg, 198, 575-9. 